\title{
Grupo de apoio psicológico a mulheres com câncer de mama: principais fantasias inconscientes ${ }^{1}$
}

\author{
Vera Lúcia Rezende ${ }^{2}$ e Neury José Botega ${ }^{3}$
}

\begin{abstract}
No Centro de Atenção Integral à Saúde da Mulher/UNICAMP a abordagem psicológica das pacientes com câncer de mama realiza-se através de Grupos de Apoio Psicológico (GAP). Os objetivos do presente estudo foram: 1. Descrever a experiência de um GAP; 2. Compreender psicodinamicamente o funcionamento do grupo, bem como o estado psicológico das pacientes. Um desses grupos foi registrado e a análise do material clínico revelou sentimentos de rejeição e desconfiança. Em sua base identificaram-se fantasias inconscientes comuns, predominando as de castração. Expor-se representava uma ameaça de mais perdas. A abordagem psicológica grupal proporcionou uma experiência de aproximação desses sentimentos, atenuando-os, e abriu às pacientes a possibilidade de um atendimento psicológico mais longo.

Palavras-chave: Psicologia, câncer de mama, psicoterapia breve, psicoterapia de grupo.
\end{abstract}

\begin{abstract}
Supportive group therapy with women with breast cancer: main unconscious fantasies This work investigated the provision of psychological assistance for women with breast cancer. The aims of this study were: 1 . to examine the experience of the Psychological Support Group established in the Centro de Atenção Integral à Saúde da Mulher (CAISM), UNICAMP, Campinas, Brasil; and, 2. to analyse the dynamic aspects of one of these groups, as well as the psychological state of the patients involved. During the sessions, the patients complained considerably and demonstrated feelings of rejection and suspicion. Several ordinary, unconscious fantasies were identified, the basis of which was a generalized fear of castration. The need to expose oneself was viewed as being full of risks and as a threat to further losses. This group psychological approach resulted in a close experience of the above feelings that allowed some of them to be dealt with.
\end{abstract}

Key words: Psychology, breast cancer, brief psychotherapy, group psychotherapy.

\section{Introdução}

O câncer de mama é uma doença freqüente, principalmente nos países mais desenvolvidos, e sua incidência tem aumentado consideravelmente a cada ano. $\mathrm{O}$ Brasil está entre os países que apresentam

1. Artigo derivado da tese de mestrado "Grupo de Apoio Psicológico a mulheres com câncer de mama; uma experiência clínica e institucional", de Vera Lúcia Rezende, Faculdade de Ciências Médicas da UNICAMP.

2. Mestre em Saúde Mental, Psicóloga no Centro de Atenção Integral à Saúde da Mulher/UNICAMP. Endereço para correspondência: Av. Júlio de Mesquita n ${ }^{\circ} 1019$ apto. 21, Cambuí, CEP 13023-065, Campinas, SP, Fone (res.): (019) 255.0357.

3. Professor Livre-Docente, Departamento de Psiquiatria da Faculdade de Ciências Médicas/UNICAMP. altas taxas de incidência (EUA: 87,0 por 100.000 mulheres; Holanda: 71,6 por 100.000 mulheres; Canadá: 68,4 por 100.000 mulheres; Brasil: 65,5 por 100.00 mulheres) (NEGRIN,1992). Em Campinas, verificouse uma incidência de 46,2 por 100.00 mulheres (BRITTO, 1993).

A tarefa de ajudar, psicologicamente, mulheres com câncer de mama, dentro de uma instituição médica, é uma experiência relativamente nova. O psicólogo necessita articular os conhecimentos teóricos a cada realidade específica, propor ajustes e estratégias capazes de atender à demanda psicológica das pacientes (nível de ansiedade, temores, defesas, expectativas etc.). Inúme- 
ros trabalhos discutem o impacto emocional do diagnóstico de câncer e da mutilação (RENNEKER \& CUTLER, 1952; DMOCH, 1985; KRYNSKI, 1986; RAMIREZ, 1989) porém o registro sobre o que tem sido oferecido em termos de ajuda psicológica aparece muito pouco na literatura. Nas duas últimas décadas, apenas 16 trabalhos foram encontrados sobre assistência psicológica a mulheres com câncer de mama, conforme pode ser observado na tabela 1.

Um dos primeiros trabalhos de reabilitação com mulheres mastectomizadas foi desenvolvido pela equipe multidisciplinar do New York Memorial Sloan Kettering Cancer Center, em 1970. Destinava-se a assistir física, social e emocionalmente todas as pacientes com câncer de mama, durante o período de internação, através de grupos diários de 90 minutos, cinco dias por semana (WINICK \& ROBBINS, 1977).

As pesquisas desenvolvidas por SPIEGEL \& BLOOM (1983) e SPIEGEL et. al. (1989) buscaram comprovar a eficiência da psicoterapia de grupo na melhora da qualidade de vida. "Os grupos visavam en-

Tabela 1. Artigos publicados nas últimas duas décadas sobre ajuda psicológica a mulheres com câncer de mama

\begin{tabular}{|c|c|c|c|c|c|}
\hline Autores & Ano & $\begin{array}{l}\text { Natureza do } \\
\text { estudo }\end{array}$ & Referencial teórico & Abordagem & $\begin{array}{l}\mathrm{N}^{0} \text { de } \\
\text { sessōes }\end{array}$ \\
\hline $\begin{array}{l}\text { WINICK \& ROBBINS } \\
\text { (EUA) }\end{array}$ & 1977 & $\begin{array}{l}\text { Relato de } \\
\text { experiência }\end{array}$ & Não oferece & Grupal & 15 \\
\hline $\begin{array}{l}\text { FLORÉZ } \\
\text { (Colômbia) }\end{array}$ & 1979 & Caso-controle & Psicanálise & Grupal & 10 \\
\hline $\begin{array}{l}\text { SACHS et. al. } \\
\text { (EUA) }\end{array}$ & 1981 & $\begin{array}{c}\text { Relato de } \\
\text { experiência }\end{array}$ & Não oferece & Grupal & 15 \\
\hline $\begin{array}{l}\text { WEIGAND et. al. } \\
\text { (Brasil) }\end{array}$ & 1982 & $\begin{array}{c}\text { Relato de } \\
\text { experiência }\end{array}$ & Não oferece & Grupal & 4 a 6 \\
\hline $\begin{array}{l}\text { SPIEGEL \& BLOOM } \\
\text { (EUA) }\end{array}$ & 1983 & Caso-controle & $\begin{array}{l}\text { Não oferece } \\
\text { (grupo de apoio e hipnose) }\end{array}$ & Grupal & aberto \\
\hline $\begin{array}{l}\text { BAHAMONDES } \\
\text { (Brasil) }\end{array}$ & 1984 & $\begin{array}{l}\text { Relato de } \\
\text { experiência }\end{array}$ & $\begin{array}{l}\text { Não oferece } \\
\text { (grupo focal) }\end{array}$ & Grupal & Até 12 \\
\hline $\begin{array}{l}\text { BAIDER et. al. } \\
\text { (Israel) }\end{array}$ & 1984 & Caso-controle & $\begin{array}{l}\text { Comportamento } \\
\text { (grupo focal) }\end{array}$ & Grupal & 12 \\
\hline $\begin{array}{l}\text { MOREIRA, GARBOVESKY, } \\
\text { CASA } \\
\text { (Argentina) }\end{array}$ & 1985 & $\begin{array}{l}\text { Relato de } \\
\text { experiência }\end{array}$ & $\begin{array}{l}\text { Psicanálise } \\
\text { (psicoterapia breve) }\end{array}$ & Individual & 10 \\
\hline $\begin{array}{l}\text { FENGLER } \\
\text { (Inglaterra) }\end{array}$ & 1985 & $\begin{array}{c}\text { Relato de } \\
\text { experiência }\end{array}$ & Auto-ajuda & Grupal & aberto \\
\hline $\begin{array}{l}\text { BRIDGE et. al. } \\
\text { (Inglaterra) }\end{array}$ & 1988 & Caso-controle & $\begin{array}{l}\text { Não oferece } \\
\text { (relaxamento e visualização) }\end{array}$ & Grupal & 6 \\
\hline $\begin{array}{l}\text { CORBINEAU } \\
\text { (Brasil) }\end{array}$ & 1989 & Caso-controle & Psicanálise & Grupal & aberto \\
\hline $\begin{array}{l}\text { SPIEGEL et. al. } \\
\text { (EUA) }\end{array}$ & 1989 & Caso-controle & $\begin{array}{l}\text { Não oferece } \\
\text { (grupo de apoio) }\end{array}$ & Grupal & aberto \\
\hline $\begin{array}{l}\text { FALLOWFIELD \& HALL } \\
\text { (Inglaterra) }\end{array}$ & 1991 & $\begin{array}{c}\text { Relato de } \\
\text { experiência }\end{array}$ & Comportamental & Individual & aberto \\
\hline $\begin{array}{l}\text { ANGELERGUES-DE-KER- } \\
\text { CHOVE } \\
\text { (França) }\end{array}$ & 1991 & $\begin{array}{l}\text { Relato de } \\
\text { experiência }\end{array}$ & Psicanálise/psicossomática & Individual & aberto \\
\hline $\begin{array}{l}\text { WILLIS } \\
\text { (Inglaterra) }\end{array}$ & 1992 & $\begin{array}{l}\text { Relato de } \\
\text { experiência }\end{array}$ & Comportamental & Individual & 6 \\
\hline $\begin{array}{l}\text { STEGERT } \\
\text { (Alemanha) }\end{array}$ & 1993 & $\begin{array}{c}\text { Relato de } \\
\text { experiência }\end{array}$ & $\begin{array}{l}\text { Não oferece } \\
\text { (grupo de encontro) }\end{array}$ & Grupal & aberto \\
\hline
\end{tabular}


corajar discussões sobre como enfrentar o câncer, expressar emoções sobre a doença e o efeito dela sobre suas vidas. Também falar sobre os problemas físicos originados pela quimioterapia ou radioterapia e a utilização de auto-hipnose para o controle da dor" (SPIEGEL et al.,1989). Mediante provas estatísticas, demonstrou-se que as "intervenções psicológicas" aumentavam consideravelmente a expectativa de vida das pacientes.

É evidente, entre os trabalhos relacionados na tabela 1 , um movimento progressivo para aprofundar o conhecimento das queixas emocionais das pacientes. Partindo de propostas com alta rotatividade de pacientes e de coordenadores, passando por trabalhos com tempo pré-fixado e número reduzido de sessões, até chegar às experiências mais recentes, de grupo aberto e sem prazo para terminar, a dificuldade maior, encontrada na literatura, diz respeito à falta de descrição mais precisa de como se desenvolveu cada trabalho. É de se estranhar que $50 \%$ dos estudos não apresentem o referencial teórico da abordagem psicoterápica utilizada.

\section{Os Grupos de Apoio \\ Psicológico (GAP)}

Nossa experiência com grupos iniciouse em 1986 e atende praticamente todas as pacientes com câncer de mama atendidas no CAISM, na Universidade Estadual de Campinas (UNICAMP). Procurou-se oferecer uma abordagem grupal que pudesse focalizar as queixas principais num breve período de tempo. Os principais objetivos do GAP são:1. Possibilitar o contato, a expressão e a abordagem dos aspectos mais subjetivos relacionados à doença e ao tratamento; 2. Possibilitar uma reflexão acerca de atitudes e comportamentos; 3 . Motivar as participantes no sentido de buscarem ajuda psicológica quando necessária.

O GAP é um grupo fechado. A coordenação é feita por profissionais da área de saúde mental, delimitando-se um número máximo de 8 pacientes por grupo, com data de início e término para as quatro sessões semanais de 1:45h.

O GAP baseia-se nas contribuições psicodinâmicas sobre grupo e psicoterapia breve institucional para pacientes somáticos (VINOGRADOV \& YALOM, 1992). A ênfase está na similaridade entre os participantes. O terapeuta busca favorecer a coesão, a troca de experiências e a diminuição do isolamento.

As intervenções têm sempre um caráter de reflexão. Não são feitas interpretações sobre a doença, mas busca-se reforçar os aspectos mais integrados e positivos da personalidade. Evita-se o aprofundamento nas experiências individuais. Sempre que possível, as comunicações dos participantes são trazidas para o foco do momento atual, no "aqui e agora", saindo de afirmações genéricas e valorizando-se as vivências nascidas dentro do próprio grupo.

O GAP tem funcionado, sistematicamente, no esquema de co-terapia, além de contar com um observador. Um dos objetivos principais deste tipo de estratégia, além de treinamento de novos profissionais, é a ampliação da faixa de observação e do poder terapêutico, através da complementação, das trocas de opinião e intuição entre os terapeutas (VINOGRADOV \& YALON, 1992).

Os objetivos deste artigo são: compreender a dinâmica de funcionamento de um GAP, bem como o estado psicológico das pacientes. 


\section{Método}

Trata-se de um estudo descritivo que, a partir da observação, da escuta e da análise detalhada das manifestações das pacientes no grupo, buscou compreender a base de seus comportamentos.

\section{Sujeitos}

Participaram deste estudo sete mulheres com câncer de mama com idade entre 34 e 58 anos, atendidas no Ambulatório de Patologia Mamária da Divisão de Oncologia do CAISM-UNICAMP. De acordo com a rotina do Programa de Reabilitação, as pacientes foram consultadas sobre o interesse em participar do Grupo de Apoio Psicológico. Normalmente, não participam destes grupos as pacientes com quadro de depressão grave, distúrbios psicóticos ou com transtornos de personalidade grave. Todas realizaram cirurgia de retirada do tumor (resseção total da mama, com ou sem reconstrução, ou uma cirurgia conservadora).

\section{Instrumentos}

Foi realizada uma entrevista aberta com cada participante, a fim de colher informações sobre as histórias de vida, confirmar os fatores de indicação para o GAP, propor o contrato terapêutico grupal e, ao final da entrevista, esclarecer os objetivos de pesquisa. Os quatro encontros grupais foram gravados em áudio e registrados por um observador.

\section{Organização e análise do material}

A gravação em áudio das quatro sessões foi transcrita e complementada pelo registro do observador. A análise do material foi feita à luz da teoria psicanalítica sobre grupoterapia, tendo como principal referência o trabalho de KÄES (1977) sobre o aparelho psíquico grupal. As sessões foram analisadas em diferentes etapas: discussão da sessão com a co-terapeuta; análise do material transcrito pela pesquisadora; discussões com o orientador; supervisão clínica da dinâmica psicológica do GAP com um psicoterapeuta de grupo da linha psicanalítica; reelaboração da análise do material, integrando todas as informações obtidas.

Dentro do referencial teórico que guiou a análise dos dados, destaca-se o conceito de fantasia inconsciente. De acordo com a concepção kleiniana, uma fantasia consiste, basicamente, em um desejo inconsciente e em uma idéia para satisfazê-lo (SEGAL, 1993). É a expressão mental de necessidades instintivas, tanto de desejos reparadores e libidinosos, quanto de destrutivos. A função dela é diminuir a tensão provocada pela falta do objeto desejado e um meio de inibir e controlar os impulsos destrutivos (ISAACS, 1982).

KÄES (1977) estudou a importância e a influência das fantasias no grupo. Observou que, tanto no processo grupal, quanto nas representações gráficas de grupo de seus pacientes, elas estavam presentes e relacionavam-se basicamente com: a origem do ser humano, nascimento, sexualidade, diferença entre os sexos, relação com o corpo materno e com outros corpos. Para o autor, elas estruturam a forma de participação e expressão dos seus integrantes. Essencialmente, o grupo vive um conflito, fruto da fantasia de repossuir o corpo materno (fusão com o grupo-mãe) e da angústia de ser destruído por ele (perda da identidade individual). De acordo com ANZIEU (1993), esta ambivalência é uma das características fundamentais das fantasias grupais. 


\section{Resultados e comentários}

As pacientes apresentaram inúmeros sentimentos e preocupações, entre os quais:

\section{O medo do desconhecido}

Refere-se ao temor do que vem pela frente (riscos de mestástases, a morte, as mudanças na vida). As pacientes desejavam ser tranqüilizadas e esclarecidas no grupo. Mostravam-se confusas e cheias de dúvidas, principalmente, sobre o tratamento e sua recuperação.

\section{O silêncio forçado do psíquico}

Verificou-se uma invasão de queixas somáticas, nas quais somente o corpo 'gritava`. As pacientes evitavam aproximar-se daquilo que sentiam. Quase não existia lugar para o pensar. A tendência era de esconder e disfarçar os sentimentos:

"Não gosto que ninguém fale de morte. Isso me perturba. Não gosto que ninguém pergunte como é que estou, eu quero esquecer."

"Não gosto de pensar no assunto, que fui operada, o que eu tive, o que vou fazer, saindo daqui não converso com ninguém, não sei se isso faz bem pra mim, se não faz, se tô certa ou errada."

"Me acho perfeita, sem doença."

\section{O medo da rejeição}

Expor-se ou abrir-se significava correr riscos. O temor predominante era o de que não seriam aceitas ou reconhecidas, mas, sim, rejeitadas:

"Pra mim isso não é coisa de se ficar mostrando para os outros."

"Os filhos reclamam do cheiro da quimio que fica na gente..."

\section{A desconfiança}

Verificou-se uma ambivalência: ora confiavam e ora desconfiavam. Estavam perdidas entre os aspectos positivos; que deviam ser preservados, e os negativos, que precisavam ser eliminados. Com muita freqüência, o negativo apareceu como uma força maior. Tudo parecia falso, não conseguiam receber ajuda sem ficar desconfiadas:

"Vocênunca foi querida na rua
e agora é oi daqui, oi dali ..."
"Não gosto do jeito da minha
mãe, do meu sogro, da minha família
me tratar, paparicando..."
"Pelo menos eu confio muito
no médico. Se ele falar que meu cabelo
vai cair e que não adianta nada fazer
alguma coisa... porque ele pensou que
eu usava tintura e disse pra eu não
usar, mas eu nunca usei tintura. En-
tão ele falou vai cair um pouco mesmo,
ele mentiu, porque vai cair bastante."

$\mathrm{Na}$ base das diferentes queixas e preocupações das pacientes, as fantasias inconscientes mais freqüentemente encontradas foram: fantasia de união-fusão; fantasia de asfixia; fantasia de castração; fantasia de quebra.

\section{Fantasias de União-Fusão:}

a fusão com a terapeuta-mãe

No GAP, as comunicações das pacientes revelaram um desejo de fusão com a terapeuta ("...mesmo quando você (terapeuta) não fala eu sei que você tá me ouvindo e me entenden$\left.d o^{\prime \prime}\right)$, traduzindo uma necessidade de estabelecer um vínculo de característica simbiótica.

As pacientes tendiam a esperar que as terapeutas pensassem por elas. Uma paciente, ainda na primeira sessão, disse: “...eu ando sem vontade de fazer as coisas, mas sinto gosto quando as colegas levam lanche 
pronto e tomamos juntas". Isso revela uma necessidade, no momento, de receber tudo pronto, ter 'tudo na boca', de não se esforçar para obter ganhos ou satisfação. Consistentemente, as pacientes lutavam para encontrar uma 'fórmula' que pudesse aliviar o sofrimento físico e mental.

KÄES (1977) descreve que as pessoas dirigem-se ao grupo como se ele representasse a imagem de um corpo (ou de parte dele), em especial, o materno: “... o regresso ao corpo pleno e redondo da mãe é o sonho por excelência" de todo grupo. Nesse sentido, o grupo, em geral, funciona como suporte projetivo desse desejo inconsciente de regresso intra-uterino: símbolo de satisfação plena e sem conflitos. Pode-se observar, no GAP, os vestígios desta inatingível busca, com base, principalmente, nas características de dependência, passividade e extrema fragilidade apresentadas pelas pacientes no grupo. De acordo com BION (1970), trata-se de um comportamento grupal que tem como base um estado afetivo arcaico, identificado como 'pressuposto básico de dependência'. Caracteriza-se pelo fato de os integrantes dirigirem-se, com freqüência, ao líder. É a idéia de que o grupo depende deste último para sobreviver.

As terapeutas, por sua vez, sentiamse acuadas e pressionadas a livrar o grupo de suas dúvidas e angústias. É como se as integrantes desejassem recuperar a saúde (emocional), sem ter que 'pagar um preço' para conhecerem a si mesmas: "A gente nem fez a prova e já quer a nota". Desejavam ter "nota" 10 antes mesmo de fazer "a prova"; obter alívio sem ter que se expressar ou se expor.

Fantasias de Asfixia:

o temor de ser rejeitada

Num movimento ambivalente, as fantasias de união-fusão dão lugar a temo- res de asfixia. Observou-se, ainda na primeira sessão, uma seqüência de queixas de desconforto no espaço físico, tais como: 'sala pequena', 'abafada'. Eram queixas de sufocamento, falta de ar, relacionadas a situações, internas e externas à instituição. As reclamações repetiram-se, também, na segunda sessão, induzindo ao questionamento sobre qual seria o sentido dessas comunicações.

Ao mesmo tempo em que as participantes sentem-se bem no pequeno grupo, como se estivessem no ventre da mãe (fantasia de vida intra-uterina), temem perder sua identidade pessoal (ANZIEU, 1993). Experimentam sentimentos e sensações conflitantes: "...eu fico aqui fechada, eu me sinto mal. Pode até ser se fosse um ambiente mais aberto eu me sentiria melhor, eu acho que é o local...".

Acredita-se que, no GAP, as queixas de asfixia das pacientes revelam o temor de não serem compreendidas ou aceitas, caso confiem suas emoções ao grupo, pois, simbolicamente, poderiam sentir-se rejeitadas. Por isso era tão difícil para as pacientes falarem sobre si mesmas no grupo. 'Fecharse' representava uma forma de proteção: "Mas é certo ou errado a gente se sentir assim? Se fechar?". Na maior parte das sessões, tentaram se esconder, ocultando os sentimentos: "...estou ótima, tudo bem. Não estou mentindo. Eu não escondo, nunca tive medo de esconder. Eu tô contente comigo...não sinto piedade de mim. Minha vida é normal. Faço tudo."

Verificou-se muita resistência para as pacientes abordarem as próprias condições atuais. Raríssimas vezes falaram ou compartilharam sentimentos sobre a mutilação sofrida. Desta maneira, supomos que os temores de asfixia estavam apoiados sobre: 1) o temor de serem anuladas, destruídas, em sua personalidade (vão "fazer $a$ minha cabeça") o temor de serem vistas so- 
mente pelas falhas ("as pessoas olham para a gente olhando o seio"), ou seja, a angústia de serem rejeitadas (expelidas).

\section{Fantasias de Castração:}

o medo de perder mais

Sabe-se que, para a mulher, a mama é um órgão altamente investido de representações, por isso, sua perda é sentida como um ataque aos aspectos femininos e narcísicos. A cirurgia é, para as pacientes, uma mutilação, uma castração. Ou seja, uma parte corporal que é perdida de forma agressiva: "Geralmente as pessoas acham que a gente arrancou tudo, que tá sem o seio...".

Arrancar lembra violência e isso parece confirmar o pressuposto da castração associado à mastectomia. É um grupo que tem em comum uma marca corporal, uma ferida externa (perda de uma imagem corporal) e, também, interna (no narcisismo, na fantasia, na auto-estima, na feminilidade): "É, a cicatriz interna a gente vai carregar a vida toda. O dificil é por dentro." O grupo sugeriu a imagem de um bebê, a quem a perda deixou cheio de ódio. De acordo com KLEIN (1982), o bebê, imerso em sua frustração, projeta seu ódio para fora, para os objetos externos, e passa a temer retaliação. As pacientes, diante de tantas perdas e privações, ficam assustadas, temendo ser novamente atacadas. Verifica-se, então, que as pacientes, além do temor da exposição e da rejeição, em conseqüência da deformidade física e emocional, parecem temer serem 'atacadas' ou 'devoradas' novamente. Cria-se, assim, um clima persecutório, que permanece no grupo em quase toda sua duração:

\footnotetext{
“...todo mundo da cidade sabe o meu problema..."

“...nem meu maridoé meu amigo, não posso nem confiar nele...".
}

Outras vezes, é como se temessem encontrar, em seu mundo interior, algo de monstruoso. Dito de outra forma, temem ver confirmada a própria agressividade ("Eu tenho até medo de pensar. Eu tenho medo de entrar em depressão. Por que comigo?"). De acordo com KLEIN (1982), não pode haver medo e angústia maiores do que a constatação da existência de aspectos destrutivos, vindos de dentro, do interior da pessoa. Nada é mais ameaçador e insuportável do que um perigo interno. Não há como fugir, nem como se defender. Nas duas situações está em jogo um predomínio das pulsões destrutivas, tanto pela fantasia de ter sido destruída, como de ter destruído.

Encontraram-se, ainda, outros comportamentos e expressões apoiados sobre a mesma fantasia de castração, confirmando sua predominância através de diferentes composições. A partir da metade da segunda sessão, observou-se que as pacientes fizeram insistentes comparações entre si. Ocuparam-se em verificar o que estava igual ou diferente: o tipo de cirurgia, o tratamento, o prognóstico e, também, o próprio corpo:

"Por que tem umas que não precisam de rádio?"

"Tem uma mulher daqui que não fez nem a quimioterapia nem a rádio. E ela tirou todo o seio!"

"A gente quer até ver o seio da outra pra saber como é que tá."

Percebe-se que os diferentes tipos de tratamento médico geravam muitas dúvidas e confusões, por exemplo, quando o tratamento de uma não era igual ao da outra. A angústia parecia diminuir na medida em que as pacientes sentiam-se mais iguais umas às outras, no grupo. 
Ao final da terceira sessão, por exemplo, verificou-se uma ênfase nos sentimentos ambivalentes de onipotência (ter tudo) e de angústia pela privação. As pacientes iniciaram suas argumentações dizendo da falta de tempo para se cuidarem. Em seguida, juntaram a essa questão a dependência do desejo do outro ("Mas isso não depende só da gente, às vezes você quer e eles não..."; "Eu tinha frutas e doces à vontade (...) faz três anos que não tô podendo pôr um na boca. "; " A felicidade completa ninguém tem!" Estão falando de perdas, limitações e impedimentos. Percebe-se que as pacientes lutavam contra a fantasia onipotente de ter tudo ("...Aié querer ganhar o céu e a terra!), ou seja, o desejo infantil de ter o pai e a mãe. Lutavam para aceitar suas limitações: "Você tem que perder pra ganhar alguma coisa". No entanto, foi na terceira sessão que as pacientes mais se aproximaram da constatação de suas perdas. Simbolicamente, foi, também, a sessão que anunciava o fim da experiência grupal. Essa sessão foi a mais longa, proporcionando a sensação de que foi 'arrastada'. Sabe-se o quanto é difícil lidar com sentimentos de perda.

De acordo com ANZIEU (1993), a fantasia de castração (idéia de que algo foi perdido) implica uma luta para que a pessoa se aceite limitada e, ao mesmo tempo, possa explorar ao máximo suas possibilidades. A própria situação grupal oferece uma oportunidade limitada. Viver esta experiência de grupo, sabendo que ela terá um fim, é uma forma de lidar com sentimentos de perda e morte. Vale a pena entregar-se ao grupo sabendo que ele irá terminar? Como viver, sabendo que se vai morrer? Perderam a sensação de invulnerabilidade (mais uma perda) e, em última instância, parecem dizer: 'se estamos doentes, o que ainda podemos construir?'

\section{Fantasias de Quebra}

No início, as pacientes estavam cheias de dúvidas e relutavam bastante em confiar. Algumas sentiam-se 'obrigadas' a participarem do GAP. Porém, ao se aproximarem do final, na última sessão, relataram ter gostado e demonstraram reconhecimento em relação ao trabalho de grupo. Disseram ter recebido apoio das pessoas ao redor (inclusive dentro da Instituição). Estavam partindo, levando uma imagem boa e desejavam demonstrar seu reconhecimento.

"Tinha uma menina ai fora, toda encolhida porque ela vai perder o bico do seio.". A menina pode simbolizar o grupo: todo encolhido diante da separação, pois ainda desejava ser bem cuidado e atendido pelos pais-terapeutas. Estavam desoladas e num conflito diante do 'desmame' do grupo ('perder o bico'). Ele havia ajudado a conter o medo da doença e do sofrimento emocional e, no entanto, as pacientes estavam percebendo que o pai-grupo iria morrer: "Eu tô com meu pai entre a vida e a morte. Tem câncer no estômago ... agora ele está morrendo...".

Para ANZIEU (1993), a criança, ao crescer, censura a mãe por ser dependente dela e luta, ambivalentemente, para separar-se (fantasias de quebra). Nos grupos, em geral, a quebra pode ser a fantasia de que a permissividade terapêutica liberte as "crianças-animais-selvagens" (aspectos inconscientes ou desintegrados da personalidade) adormecidas dentro de cada participante e, como conseqüência, eles entredilacerariam-se até o fim.

As pacientes relataram uma experiência no grupo, e, de uma forma impressionante, parece confirmar a angústia diante da repetição desta 'rachadura':

“Eu li um livro de uma pessoa que passou o que a gente passou. Con- 
ta que tinha um câncer no estômago, $e$ que tava comendo todo o seu estômago, afundando a pele dele e não tinha mais cura com a medicina. Então eles resolveram fazer uma experiência de colocar carne no estômago dele e o câncer ao invés de comer o estômago, comia a carne. Daí houve uma conversa de que suco de uva curava o câncer. Como ele estava entre a vida e a morte, resolveram colocar suco de uva em cima, no estômago. O tumor começou a morrer, e ele ficou curado, cicatrizou. Então no meu estômago não cai nem um pedacinho de carne."

Parece que essa história, ao mesmo tempo em que é uma irrealidade, é, também, uma metáfora do que estava se passando com elas, no 'aqui e agora' do grupo. Do ponto de vista psíquico, a situação relatada parece representar os próprios conteúdos internos, os impulsos de vida (os aspectos reparadores, os sentimentos de gratidão) e os de morte (a parte mais primitiva, desintegrada, as 'crianças-animaisselvagens'). $\mathrm{Na}$ experiência imediata do grupo, pode-se pensar que ele ajudava a digerir as 'emoções cancerígenas' (mal que a medicina não cura). A experiência à qual se referiam consistia em não fazer mais a digestão, deixar de ingerir os alimentos (potencialmente danosos). A digestão acontecia fora do estômago. Se iam perder o grupo-estômago, como iam 'digerir' suas emoções danosas?

É interessante enfatizar que as pacientes não foram espontaneamente em busca de ajuda psicológica. Ao contrário, estavam muito resistentes (..."às vezes a gente chega a Deus não por amor mas por dor"...). FALLOWFILD \& HALL(1991) descreveram que é raro uma mulher, acometida por câncer de mama, solicitar qualquer tipo de assistência psicológica. $\mathrm{O}$ mais comum é observar-se um sofrimento solitário, nem sequer reconhecido pelas pessoas ao redor.

A questão fundamental, imposta pelas dúvidas e incertezas diante da assistência psicológica para essas pacientes, talvez tenha sua origem, justamente, neste ponto, ou seja, diminuir as resistências. A tendência das pacientes em esconder e negar os sentimentos foi muito maior do que a inclinação à aproximação. Expor-se ou abrir-se significava correr riscos. A fantasia predominante era a de que poderiam sofrer mais perdas com a exposição. A função do GAP foi proporcionar um espaço para a reflexão a respeito dos riscos de falar sobre o que se sente. Ainda que se fechar parecesse mais seguro, as pacientes se 'cansavam' de 'disfarçar'.

Após as pacientes manifestarem suas ansiedades e temores, entrando em contato com suas emoções, mas sem cair em depressão profunda (conforme temiam), tranqüilizaram-se. Somente quando os sentimentos de desconfiança diminuíram é que as pacientes começaram a sentir algum tipo de ganho:

$$
\text { “...você vai vendo que está todo }
$$
mundo num mesmo barco e começa a sentir uma ajuda."

\section{Referências Bibliográficas}

Angelergues-De Kerchove, C. - Et "la mort viendra...": des psychothérapies de patients atteints de maladies létales. Rev. Franç. Psychanal., 3: 659-66, 1991.

Anzieu, D. - O grupoe o inconsciente: o imaginário grupal. São Paulo, Casa do Psicólogo, 1993. 227p.

Baider, L.; Mikm, J.C.; De-Nour, K. - Time-limited thematic group with post-mastectomy patients. J. Psych. Res., 28(4):323-30, 1984. 
Bahamondes, M.Y.M. - Recuperação física e emocional das mastectomizadas. In: Pinotti, J.A., ed. - Terapêutica em mastologia. São Paulo, Manole, 1984. p.111-5.

Bion, W.R. - Experiências com grupos. 2ed. Rio de Janeiro, Imago, 1970. 185p.

Bridge, L.R.;Benson, P.; Pietroni, P.C.; Piest, R.G. - Relaxation and imagery in the treatment of breast cancer. BMJ 297 (5): 116972, 1988.

Britto, A.V. (ed) - Registro de câncer de base populacional de Campinas: dados de 1991. Universidade Estadual de Campinas, Campinas, São Paulo, 1993, 8p.

Corbineau, G.D. - Um grupo de pacientes mastectomizadas: aplicações da psicanálise no trabalho institucional. Infor. Psiq. 8(1): 10-8, 1989.

Dmoch, W. - Sobre alguns aspectos do procedimento com pacientes mastectomizadas. In: Prill, H.J. \& Langen, D. - Ginecologia psicossomática: o caminho psicossomático para a prática ginecológica. São Paulo, Roca, 1985. p.315-9.

Fallowfield, L.J. \& Hall, A. - Psychosocial and sexual imapct of diagnosis and treatment of breast cancer. Br.Med. Bull., 47 (2):388-99, 1991.

Fengler, J.- Grupos de auto-ajuda de mulheres cancerosas. In: Prill, H.J. \& Langen, D. - Ginecologia psicossomática: o caminho psicossomático para a prática ginecológica. São Paulo, Roca, 1985. p.320-26.

Flórez, H.B. - Psicoterapia de grupo en pacientes de cancer. Rev. Lat. Am. Psicol., 2 (1): 4763, 1979.

Isaacs, S. - A natureza e a função da fantasia. In: Klein, M; Heimann, P; Isaacs, S; Riviere, J. Os progressos da psicanálise. 2ed. Rio de Janeiro, Guanabara Koogan, 1982. 9-135.

Käes, R. - El aparato psíquico grupal: construcciones de grupo. Barcelona, Granica, 1977.347p.

Klein, M. - Algumas conclusões teóricas sobre a vida emocional do bebê. In: Klein, M; Heimann, P; Isaacs, S; Riviere, J. - Os progressos da psicanálise. 3ed. Rio de Janeiro, Guanabara Koogan, 1982. p 216-55.

Krynski, S. - Reações psicológicas e psicopatológicas relacionadas à cirurgia da mama. Bol. CEPP 4 (2): 59-65, 1986.
Moreira, P.; Garbovesky, C.; Casá, D. - Psicoterapia en pacientes mastectomizadas. Revista Argentina de cirugia, 49: 119-20, 1985.

Negrin, L.C. - Epidemiologia del cancer de la glandula mamaria. In: Muñoz, G. A. H., ed. Avances en mastología. Caracas, Ed. Universitaria, 1992. p.155-64.

Ramirez, A.J. - Liaison psychiatry in a breast cancer unit. Royal Soc. Med., 82: 15-7, 1989.

Renneker, R.M.D. \& Cutler, M.M.D. - Psychological problems of adjustment to cancer of the breast. J. Am. Med. Assi., 148(10): 833-8, 1952.

Sachs, S.H.; Davis, M.; Reynolds, S.A.; Spagnola, M.; Hall, P; Bloch, A. - Comparative results of postmastectomy rehabilitation in a specialized and community hospital. Cancer 48: 1251-5, 1981.

Segal, H. - Sonho, fantasia e arte. Rio de Janeiro, Imago, 1993.132p. (Coleção Nova Biblioteca de Psicanálise).

Spiegel, D. \& Bloom, J.R. - Group therapy and hypnosis reduce metastatic breast carcinoma pain. Psychosom. Med., 45 (4): 333-9, 1983.

Spiegel, D.; Kraemer, H.C.; Bloom, J.R.; Gottheil, E. - Effect of psychosocial treatment on survival of patients with metastatic breast cancer. The Lancet, 14: 888-91, 1989.

Stegert, O. A. - Psychological management of breast cancer patients in a group. Z-Lymphol 17 (1): 15-7, 1993.

Vinogradov, S. \& Yalon, I.D. - Manual de psicoterapia de grupo. Porto Alegre, Artes Médicas, 1992. 215p.

Weigand, O.; Souza, A.Z. De; Okawara, H.; Costa,E.C.; Savatore, C.A. - Reabilitação pós-mastectomia. Rev. Ass. Med. Bras., 28(56): 143-47, 1982.

Willis, J. - Building on strengths. Nursing times 88(15) 21, 1992.

Winick, L. \& Robbins, G.F. - Physical and psychologic readjustment after mastectomy: an evaluation of Memorial Hospital's PMRG Program. Cancer 39: 478-86, 1977. 